\title{
OCCUPATIONAL VOICE DISORDERS IN SLOVAKIA TODAY AND IN THE PAST
}

\author{
Mikolajcikova M, Ferencikova V, Fiolkova K, Sokolikova V, Matuskova Z, Osina O.
}

Clinic of Occupational Medicine and Toxicology, Jessenius Faculty of Medicine in Martin, Comenius University in Bratislava, and Martin University Hospital, Martin, Slovak Republic

\section{A b s tract}

Introduction: Voice disorders primarily affect workers in professions with increased voice demands, such as teaching personnel in educational system, singers, lecturers, actors or managers. Severe voice disorders often require a permanent change of work position.

Methods: Retrospective analysis of a set of patients with occupational voice disorders who were hospitalized at the Clinic of Occupational Medicine and Toxicology, Martin University Hospital (COMaT, MUH) in the years of 2000-2017. Comparison of the data obtained with the National Centre of Medical Information (NCMI) data on the occurrence of occupational voice disorders throughout the Slovak Republic (SR). Comparison with the retrospective analysis of reported occupational voice disorders in the years of 1967-1996. Case report of a patient with an occupational voice disorder.

Results: We point to a long-term low incidence of occupational voice disorders. In the years of 2000-2017, 24 cases of occupational voice disorders were reported in Slovakia, of which 20 cases were reported under item 42-1 and 4 cases under item 42-2 in the List of Occupational Diseases. Through the COMaT, MUH 11 cases of occupational voice disorders were reported during these years, of which 9 cases were listed under item $42-1$ and 2 cases under item 42-2. From 1967 to 1996 there were 52 occupational voice disorders reported in Slovakia, of which 45 were under item $42-1$ and 7 under item $42-2$.

Conclusions: As there is a tendency to underestimate the voice difficulties among teaching staff, it is necessary to provide better information about the possible consequences, prevention, and treatment of these diseases. All of this should be in the competency of occupational health services.

Key words: voice disorder, dysphonia, occupational

\section{INTRODUCTION}

Voice is one of the fundamental means of interpersonal communication, very sensitively mediating emotions, attitudes, and psychological being of people (1). In some professions associated with great voice demands it is also used as a working tool. There are many different classifications of these professions in literature, while most frequently used is categorization into two groups. The first one is a group of voice professionals, including singers (soloists and chorus singers), actors, teachers, professional speakers, and anchormen. The second group is represented by professions with increased demands on voice, such as judges, doctors, politicians, managers, clergy, and salespersons. In the first group severe voice disorders often require a permanent change of work position (2). In the second group the voice disorders are not desirable but they do not jeopardize the ability to perform a profession (1). Occupational voice disorders are relatively rarely occurring occupational diseases. In the List of Occupational Diseases (Annex No. 1 to Act No. 461/2003 Coll.) are listed as an item:

42-1 Severe hyperkinetic dysphonia, vocal fold nodules, or severe vocal cord insufficiency, that make performing any vocally demanding profession impossible.

42-2 Severe phonasthenia (3).

Corresponding author:

Martina Mikolajčiková, MUDr, Clinic of Occupational Medicine and Toxicology, JFM CU and Martin University Hospital, Martin, Kollárova Str. 2, 03659 Martin, Slovakia

Phone: +421 434203 817; e-mail: mikolajcikovamartina@gmail.com 
Etiologically, various causes are involved in the development of voice disorders, regarding the complex process of phonation. Voice formation is composed of three mechanisms: breathing, phonation, and articulation. Changes to any of these mechanisms may result in a voice disorder requiring professional care. Voice disorders can be divided into organic and functional (4).

Organic disorders develop due to an organic pathological finding on the vocal system. The causes can be congenital anomalies, acute and chronic inflammations, tumors, laryngeal innervation disorders, injuries, postoperative states and hormonal disorders, negative influence of smoking (both active and passive), alcohol and drugs, environmental influences. These changes can be temporary or permanent (1).

Functional voice disorders are defined as voice impairment without obvious organic findings on the voice apparatus or with organic findings that are completely reversible after changing voice habits or after voice therapy. These disorders develop due to incorrect use and misuse of voice, such as shouting, creating non-physiological sounds, habitual non-physiological coughing, throat cleaning, psycho-emotional factors, especially work-related stress. Studies have shown that the most critical factor in the development of vocal cord injury is time needed for regeneration of vocal cords. Therefore, the most vulnerable group is teaching staff as they have a minimum amount of time for vocal regeneration comparing to other voice professionals (1).

In this paper we are going to focus more on the voice disorders that can be reported as occupational diseases in Slovakia.

The basis of hyperkinetic dysphonia is discoordination of the activity of vocal system components (hyperactivity of the expiratory muscles, vocal adductors, and external laryngeal muscles) with reduced use of resonance spaces (5). Sequentially, organic changes occur: vocal muscle hypertrophy due to excessive vocal exertion with a consequent insufficiency of glottis due to thickening of vocal folds caused by vocal muscles hypertrophy. Risk factors include excessive increasing of voice intensity in noisy environment, overexertion of its height and strength, inhalatory exposure to chemicals and allergens, inadequate rest, chronic airway infections, incorrect or no voice technique, and nicotinism (both active and passive) (6). Frequently, it is also found in children singing in choirs with unprofessional leadership where wrong singing stereotypes are fixed (4). Patients state impaired quality and increased voice fatigue, reduced voice range, paresthesia before and after phonation. In the patient examination dominates hoarseness, increased tension in the cervical muscles, increased cervical veins volume, phonation is pushed, followed by voice failure. The laryngoscopic image shows a sand-glass shaped glottis. Laryngostroboscopic examination in the closing phase reveals typically increased tension of vocal folds with smaller amplitude of oscillations (6). The treatment of hyperkinetic dysphonia is based on maintaining voice hygiene and voice re-education. As for the medicamentous therapy, early and thorough treatment of respiratory infections is important, with application of antibiotics, mucolytics, and decongestants, if necessary. If this problem stays not solved for a long time, signs of organic damage can occur when vocal cord nodules or polyps are formed, possibly also vocal muscle atrophy and a hypokinetic dysphonia appears (7).

Fig. 1 A - normal glottis, B - vocal muscle hypertrophy Available from:

http://quizlet.com/51 19996/laryngeal-physiology-flash-cards/

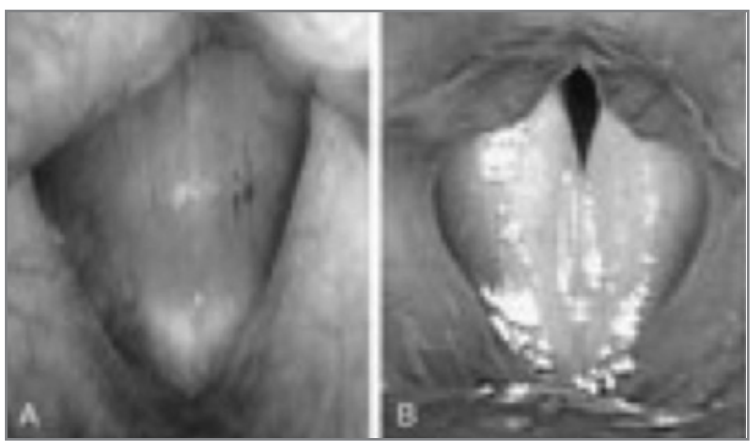


Voice over-exertion and incorrect voice technique can lead to vocal cord nodules formation (8). In the case of non-compliance with vocal hygiene practices a hematoma is formed, which organizes eventually. At the interface of the front and the middle third of the vocal cord arises thickening predisposed to the creation of a vocal cord nodule (6). In the phase of subepithelial edema the nodules are reversible, after organic changes they are irreversible. The nodes are usually formed on both vocal cords resulting in incomplete closure of the vocal cords depending on the size and position of the nodule (7). Nodules are more common in women. The voice is hoarse with a breathy murmur. The basis of treatment is education about voice hygiene, adequate hydration, and avoiding misuse and exertion of voice. Surgical treatment is based on gentle removal of nodules and subepithelial edema. It is indicated especially if, despite adherence to medication and appropriate voice therapy, unacceptable voice impairment persists. Rare indications are cases where airway patency is compromised or if there is a risk of malignancy. It is always necessary to do histopathological examination of the lesions. Without adhering to regime measures the recurrence of organic vocal damage is almost certain (5).

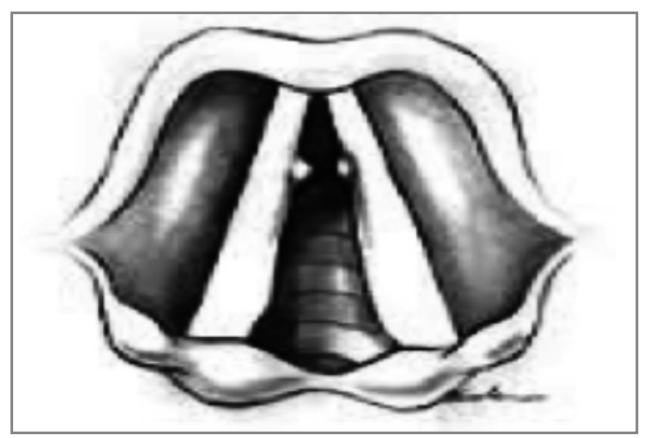

Fig. 2 Vocal cord nodules Available from: http://www.voicedoctorla.com/voicedisorders/vocal-nodules-nodes/

Hypokinetic dysphonia develops due to vocal muscle atrophy and occurs mainly after the 45 th year of life because of general weakening of the organism (9). It may occur secondary to hyperkinetic dysphonia as its next stage but it can also be a primary congenital illness. The voice with hypokinetic dysphonia has a characteristic breathy admixture; it is hoarse, less resonant, and easily tired. During the long conversation it is gradually weakening. As a result of effort to compensate for the glottis isufficiency spasticity can occur (7). Typical laryngoscopic finding is the incomplete closure of glottis which has a concave or biconcave (fusiform) shape. Stroboscopic examination is dominated by reduced vocal tension, amplitude of oscillations is increased. Treatment is strictly conservative, using group B vitamins and voice therapy for correct voice sitting, vocal usage, and adhering to voice hygiene (10).
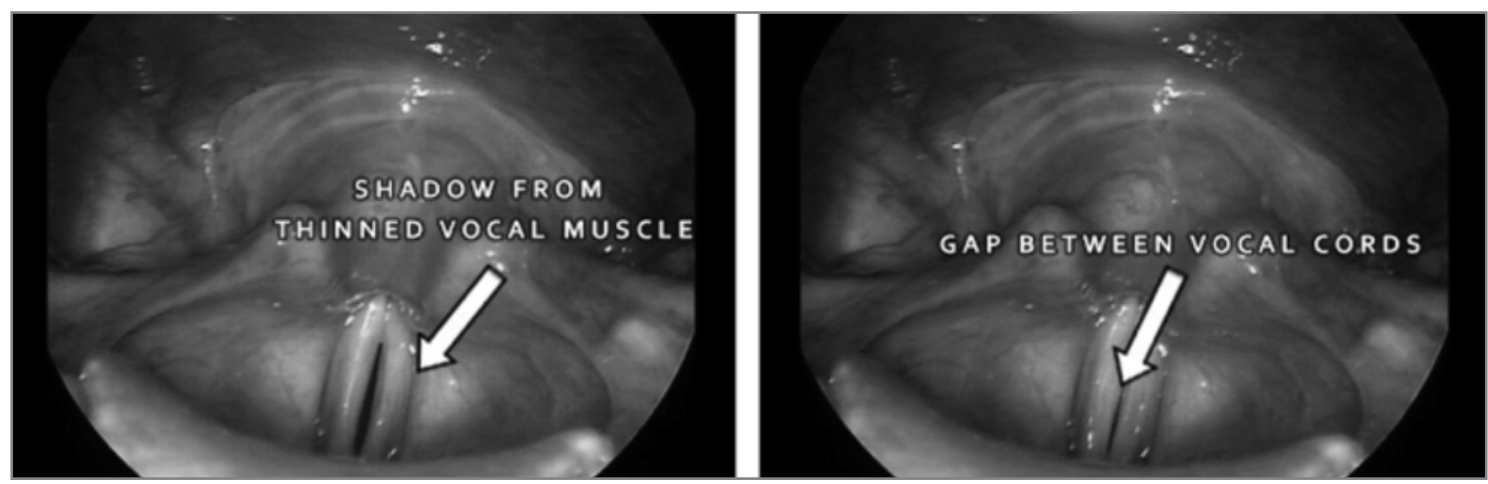

Fig. 3 Laryngoscopic image of hypokinetic dysphonia

Available from: http://www.voicedoctorla.com/voice-disorders/vocal-atrophy/ 
Phonastenia is one of the so-called psychogenic voice disorders (2). It is the inability to create a high quality sung or spoken voice in voice professionals. This disorder develops primarilly due to psychological tension, psychological instability, and increased emotional involvement in stressful situations (1). The voice professional is afraid of a possible voice failure resulting in faster voice fatigue and stagnation of the modulation ability of voice. They feel constriction, burning and scratching in the throat, and finally the voice fails. Singers may experience tremolo or dystonia, in severe cases even spastic aphonia appears. Typically, speaking voice, laughter, and cough in these patients are resonant or only minimally affected. The laryngoscopic and laryngostroboscopic findings are physiological. Treatment of psychogenic voice disorder is usually very demanding. Common speech re-education is less effective so psychotherapy and breathing exercises are recommended (10).

\section{METHODS}

Retrospective analysis of a set of patients with reported occupational voice disorder in COMaT, MUH in the years of $2000-2017$. Comparison of the data obtained with the data of the National Centre of Medical Information (NCMI) on the occurrence of these diseases throughout the Slovak Republic (SR) in the same time period (11). Comparison with the retrospective analysis of reported occupational voice disorders in the years of 1967-1996 (12). Demonstration of reported occupational disease by a case report.

\section{RESULTS}

In the years of 2000-2017, 8 occupational voice disorders were reported at COMaT, MUH of which 6 cases as an item $42-1$ and 2 cases as item $42-2$. The average age of the subjects at the time of reporting the occupational disease was $54.7 \pm 4.7$ years and the average exposure duration was $30.7 \pm 5.4$ years.

The patients in our set were mostly women (seven patients), only in 1 case of reported occupational voice disorder it was a male patient.

Five patients in our set were teaching at a primary school, one at a secondary school, one at a nursery school, and one as a special pedagogue in different facilities (special school, nursery school, vocational school) as shown in Figure 4.

Fig. 4 Representation of the professions in the set

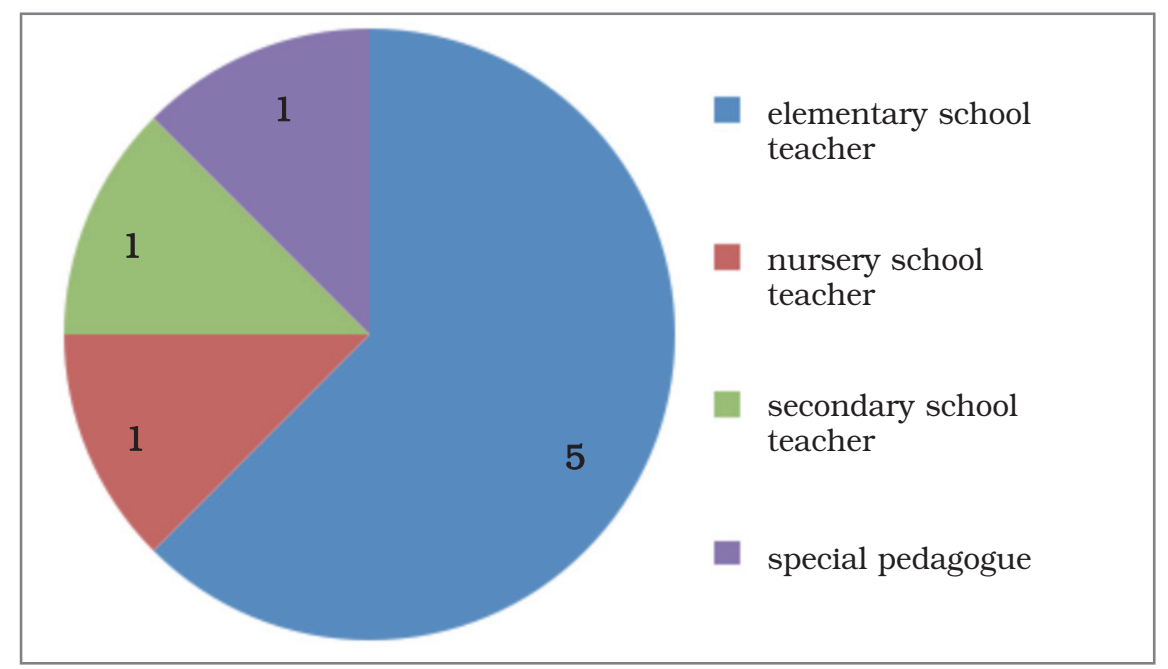


According to NCMI data 24 occupational voice disorders were reported in Slovakia in the years of 2000-2017, of which 20 cases as item 42-1, 4 cases as item 42-2 (Fig. 5). Of the total number of all reported occupational diseases during this period (8.218) occupational voice disorders represent $0.29 \%$ (11).

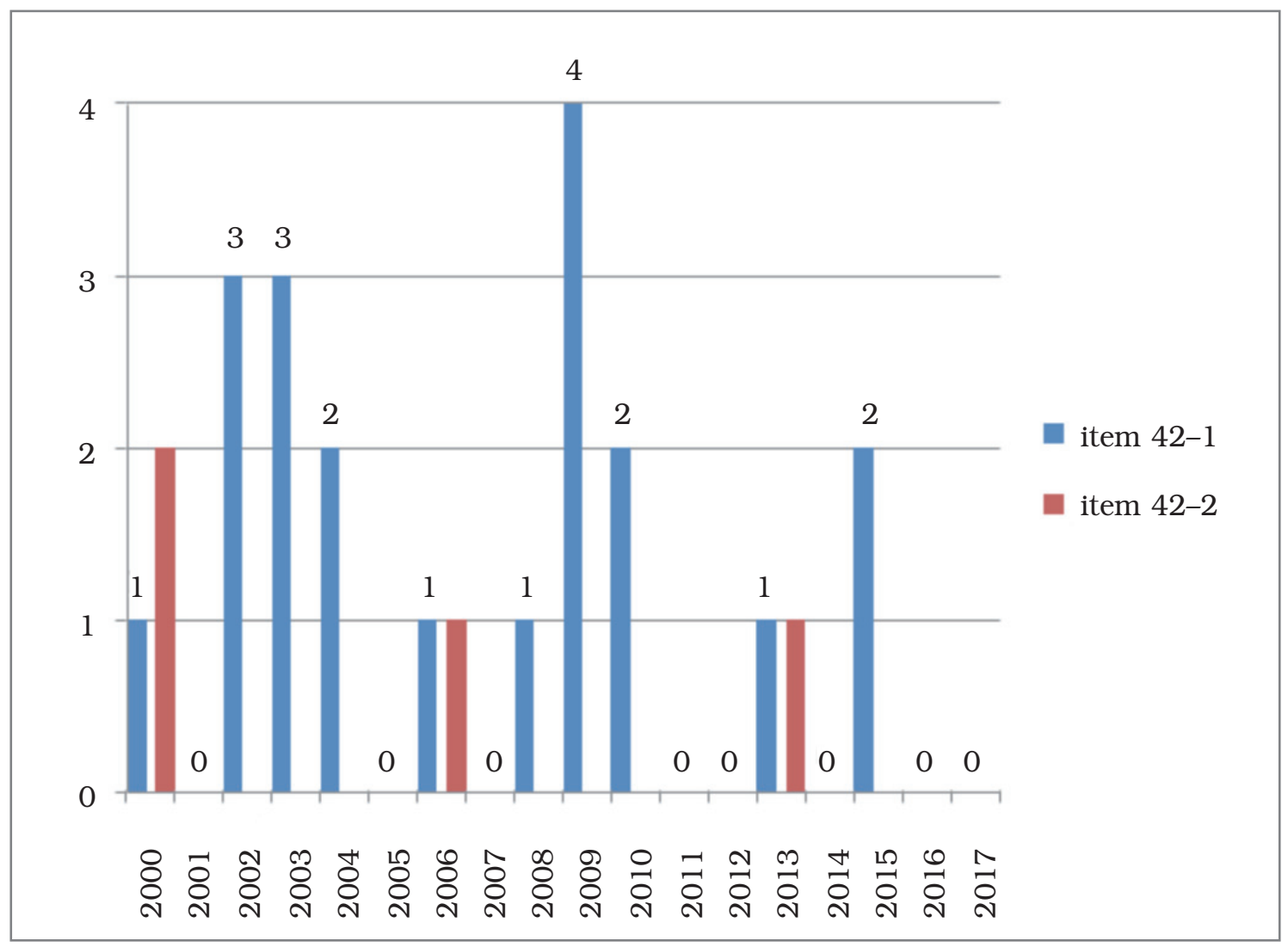

Fig. 5 Development of the number of reported occupational voice disorders in the SR in 2000-2017. NCMI, 2018

In the years of 1977 - 1996140 occupational voice disorders were reported in the SR. Between 1967 and 199652 occupational voice disorders were reported through COMaT, MUH, of which 45 were reported as vocal cord insufficiency and 7 as phonasthenia (12).

\section{A case report}

A 58-year-old patient had been working totally for about 26 years for various employers as a manager, consultant and adviser. In recent 16 years he was working for his last employer as a chairman of the board of directors, consultant, adviser, and a lecturer in a company focused on consulting and advisory activities. As a consultant and adviser he advised clients in their economic activities, financial management, business and marketing, in developing business plans, negotiating with banks, customers, suppliers. He was also working as an expert, trainer, and lecturer in the field of system management, financial management. In all of these activities he was using his voice.

The first phoniatric examination of the patient was carried out after 17 years of work with increased vocal demands. The patient was repeatedly examined at the otorhinolaryngology 
and treated with antibiotics for recurrent and prolonged laryngitis, laryngotracheitis with objective finding of vocal cords edema. The patient stated episodes of hoarseness and deteriorating voice quality at the end of the working week, eventually with complete voice failure. In the next examination the vocal cords insufficiency was identified. The left vocal cord was paretic but other causes of paresis were excluded. For these difficulties he began to attend a phoniatrician where he was diagnosed with spastic dysphonia, phonasthenia, and subsequently underwent voice rehabilitation. However, he could no longer perform his previous occupation; therefore, he had to go on a long-term sick leave. After verifying the occupational exposure to increased voice use demands we reported an occupational disease: Severe vocal cords insufficiency.

\section{DISCUSSION AND CONCLUSIONS}

The voice load of teaching professionals is not being declared as a high risk job in our legislation. However, this does not exclude possibility of development of occupational voice disorder. In various educational facilities (e.g. primary school, university) there is a different risk of voice injury considering particular voice load. Evaluation of risk is the competence of the public health authority.

When comparing statistics from previous years about the occurrence of occupational voice disorders there was a significant decrease in reported cases both in the SR and COMaT, MUH in the last 18 years (11). The decrease in the number of reported occupational diseases is explained mainly by dissimulation and underestimation of difficulties by teaching staff mainly due to existential reasons.

In our analysed set were also a higher average age and an average length of exposure at the time of reporting the occupational disease. In our set the prevalence of women correlated with the published data about the more frequent occurrence of occupational voice disorders in the female population $(12,13,14)$. Mostly affected professions were primary school teachers.

Voice disorders are especially affecting teaching staff as there is an increased demand on voice and minimal time for vocal regeneration after exertion. In the case report we show a case of a lecturer who lost the ability to work in his profession because of long-term difficulties with voice causing repeated sick leaves.

Preventive measures should be based on the vocal education of future voice professionals focused on the correct formation and use of voice already during their studies. However, the vocal technique is actually taught only in the study programs of future teachers of art-educational subjects. Both the schedule of lessons and the number of weekly taught hours should also be taken into consideration to avoid increased voice exertion.

Occupation with excessive use of voice is not suitable for people with changes in vocal cords, nodules, polyps, recurrent or chronic airway infections, more severe allergic diseases, neurological disorders affecting the predilection area, and severe hearing loss, which automatically leads to increasing strength of voice (2).

It is also important to eliminate the factors contributing to the manifestation of voice disorders such as smoking, dusty and noisy environments, rooms with inappropriate acoustics, unfavourable microclimatic conditions, increased amount of lessons and stressful situations in the prevention of occupational voice impairment.

Voice hygiene plays a key role in the prevention as well as in re-education of voice disorders. Its principles include proper diet, training of correct breathing, preventing exertion of vocal cords, especially in the period of convalescence after respiratory infections and in women during menstruation. It is important to remove the unfavourable voice habits such as throat cleaning (2). Regular voice exercises and preventive medical examinations are essential. Knowledge of, as well as compliance with the listed precautionary measures can be helpful to reduce the incidence of these occupational diseases. 
On the basis of this study we can conclude that the decrease in the number of reported occupational diseases is not only due to underestimation of difficulties on the side of teaching staff. It is also very likely that the general practitioners and otorhinolaryngologists do not have enough information about the system of reporting and compenstating for occupational diseases to provide their patientes.

\section{REFERENCES}

1. Kerekrétiová A. Stres ako etiologický faktor vzniku porúch hlasu u hlasových profesionálov. Speciální predagogika 2006; 16(2): 106-14.

2. Buchancová J, Hajtman A. Profesionálne poruchy hlasu. In: Buchancová J et al. Pracovné lekárstvo a toxikológia. 1st ed. Martin: Osveta; 2003; 837-9. Buchancová J et al. Pracovné lekárstvo. Slovakia: Martin; 2003.

3. Act No. 461/2003 Coll. On Social Insurance. Available from: http://www.zakonypreludi.sk/zz/ 2003-461.

4. Hahn A et al. Otorinolaryngologie a foniatrie v současné praxi. Czech Republic: Praha; 2007.

5. Přiručka pro praxi: Hyperkinetická dysfonie. ČLS JEP 2013.

6. Veldová Z. Možnosti léčby hlasových profesionálů v ambulantní praxi. Interní med 2005; 7(11), 496-8.

7. Kučera M, Frič M, Haliř M. Praktický kurz hlasové rehabilitace a reedukace. Czech Republic: Opočno; 2010.

8. Pelclová D et al. Nemoci z povolání a intoxikace. Czech Republic: Praha; 2014.

9. Hybášek I. eOtorinolaryngologie, verze I. Czech Republic: Hradec Králové: 2018.

10. Hlasové funkčné poruchy u dospelých. 2016. Available from: http://www.orl-lfuk.sk/ żhlasove_funkcne_poruchy_u_dospelych.php.

11. Choroby $z$ povolania alebo ohrozenia chorobou $z$ povolania v SR v r 2017. NCZI, 6/2018. Available from: http://www.nczisk.sk/Documents/publikacie/2017/zs1806.pdf.

12. Buchancová J, Krutý F, Klimentová G, Hajtman A, Legáth L, Kludajová E, Fridrich J. Profesionálne choroby v rezorte školstva a vedy v rokoch 1967 - 96. Pracov Lék 1997; 49(4): 165-71.

13. Palomino Moreno MP, Hoyo Rodríguez A, García López V, Losantos Martínez JT. Functional dysphonia and vocal cord nodules in teachers in Navarra, Spain. Arch Prev Riesgos Labor 2013; 16(4): 182-6.

14. Nerrière E, Vercambre MN, Gilbert F, Kovess-Masféty V. Voice disorders and mental health in teachers: a cross-sectional nationwide study. BMC Public Health 2009, 9: 370.

15. Buckmire RA. Vocal Polyps and Nodules. 2013. Available from: http://emedicine.medscape.com/ article / 864565-overview.

Received:November, 26, 2018

Accepted: January, 30, 2019 